\title{
Retransmisiones futbolísticas televisivas en España: perspectiva histórica de una relación de necesidad (1956-1988)
}

\author{
Joseba BONAUT IRIARTE \\ Universidad San Jorge \\ jbonaut@usj.es
}

Recibido: 4 de octubre de 2012.

Aceptado: 20 de octubre de 2012.

\begin{abstract}
Resumen
El vínculo entre la televisión española y el fútbol es cada vez más evidente y poderoso. Sin embargo, este no es un fenómeno nuevo. La mayor parte de los rasgos de esta unión se gestaron desde los orígenes del propio medio y a lo largo de los años han creado una relación de necesidad mutua en la que ambas partes han salido beneficiadas. Tanto los beneficios como los perjuicios de la relación entre la televisión y el fútbol han marcado profundamente el desarrollo histórico del medio durante los últimos 15 años. El nacimiento de las televisiones comerciales, la irrupción de las plataformas digitales y las nuevas redes de cable, la fusión de las empresas dedicadas a la televisión digital o la concesión de las nuevas licencias televisivas son algunos de los principales acontecimientos que ha vivido el mundo televisivo en este tiempo. En todos ellos, el fútbol ha jugado un papel esencial. Sin embargo, no es un fenómeno nuevo. Este artículo pretende analizar en profundidad las características de esta relación de necesidad desde sus orígenes y durante el período del monopolio de la televisión pública (1956-1988). Así se podrá determinar la influencia que tuvieron estos contenidos en el desarrollo histórico de la televisión y establecer unas conclusiones sólidas sobre una realidad actual en la que el fútbol es el principal motor en la programación de las cadenas públicas y privadas.
\end{abstract}

Palabras clave: Televisión; fútbol; relación; necesidad; España.

\section{Spanish football TV broadcasts: a historical perspective of an interpendent relationship (1956-1988)}

\begin{abstract}
Today, the relationship between Spanish television and football is becoming more obvious and powerful. However, this is not a new phenomenon. Most of the features of this union were born with the creation of Spanish TV and over the years they have created a relationship of mutual need. Both the benefits and harms of the relationship between television and football have profoundly marked the historical development of the medium for the last 15 years. The birth of commercial television, the emergence of new digital platforms and cable networks, the merger of companies devoted to digital television or the granting of new TV licenses are some of the major events of the Spanish TV History. In each one of these events, football has played an essential role. However, this is not a new phenomenom. This article would make an in-depth analysis of this relationship and will determine the real influence of football broadcasts in the historical development of Spanish TV, especially in the period of the monopoly of public television (1956-1988). In the end, some conclusions will arise around today's Sports programming strategies.
\end{abstract}

Key words: Television; football; interdependent;relationship; Spain. 


\section{Referencia normalizada}

Bonaut Iriarte, J. (2012). Retransmisiones futbolísticas televisivas en España: perspectiva histórica de una relación de necesidad (1956-1988). Historia y Comunicación Social, Vol. 17, páginas 249-268.

Sumario: 1. Introducción. 2. Estado de la cuestión y metodología. 3. Los orígenes televisivos del fútbol en España. 4. Fútbol y televisión durante el monopolio de la televisión pública (1956-1988). 4.1. El fútbol como motor de desarrollo de la televisión. 4.2. Relación de necesidad, relación problemática. 5. Conclusiones. 6. Bibliografía.

\section{Introducción}

El deporte, y en especial el fútbol, ha jugado un papel clave en el desarrollo televisivo español. Actualmente sería difícil imaginarnos un gran acontecimiento futbolístico sin la presencia de las cámaras televisivas, al igual que no podríamos considerar la construcción de una parrilla programática televisiva sin el fundamental papel del deporte "rey".

La relación de necesidad entre estos dos agentes es cada vez más fuerte y visible para los espectadores e incluso para la comunidad científica que, en los últimos años, ha prestado una importante atención a la influencia del fútbol en la construcción programática televisiva, así como el papel decisivo en la consolidación del negocio televisivo (especialmente representado en la ya famosa lucha por los derechos de retransmisión).

El interés creciente sobre el tema nos ofrece una buena oportunidad para escarbar en los orígenes de la relación en nuestro país y determinar el modo en que tanto la televisión como el fútbol se han influenciado en su particular crecimiento y desarrollo hasta el actual período de televisión comercial. Por ello, este texto tratará de profundizar en esos rasgos que caracterizan a esta relación de necesidad en nuestro país a través de una perspectiva histórica. Se analizará el período previo a la aparición de las primeras emisiones regulares televisivas y se comparará la situación española con la de otras potencias económicas del momento. Posteriormente, el análisis se centrará en la etapa de monopolio de la televisión pública desde dos perspectivas: la influencia del fútbol en el nacimiento, crecimiento y desarrollo de la televisión española y, en segundo lugar, los principales problemas y desventajas de la relación en el período.

El objetivo es determinar, en buena medida, de qué manera las retransmisiones futbolísticas han permitido el desarrollo y evolución del medio televisivo en España, han condicionado su estructuración, gestión y política de programación. Por otro lado, explicar cómo la televisión ha marcado el desarrollo y la evolución del fútbol como deporte y, especialmente, como negocio.

La exploración de los beneficios y perjuicios de esta relación de necesidad es decisiva para entender la dimensión comunicativa del deporte que se presenta en este número especial. Y, como siempre, la clave para entender un fenómeno tan complejo es la historia. 


\section{Estado de la cuestión y metodología.}

A pesar de la fuerte incidencia del fútbol en la evolución histórica de la televisión en nuestro país, este tema ha pasado prácticamente desapercibido en el ámbito académico. Si bien en los últimos años ha suscitado algo de interés, ha sido un fenómeno aislado y muy restringido a publicaciones informativas (no académicas) del entorno económico como el diario Expansión, y siempre centrada en un aspecto muy concreto como es el de la lucha por los derechos de retransmisión futbolística.

Si hablamos desde una perspectiva más amplia, la propia de la dimensión comunicativa y su relación con el deporte, también los esfuerzos académicos han sido muy reducidos y limitados a unos pocos autores. Desde un enfoque muy general, podemos encontrar la obra de Antonio Alcoba, Deporte y Comunicación (1997), o en aspectos más particulares de la relación entre deporte y televisión, el estudio de Josep María Blanco Pont sobre las retransmisiones deportivas, Las retransmisiones deportivas televisadas como género periodístico, espectacular y dramático (2000), o la tesis doctoral acerca de la programación deportiva de la televisión gallega de Aurora Varela, Las audiencias de las retransmisiones y programas de deportes de televisión de Galicia desde 1990 hasta 1996 (1997). Más interesante y precisa resulta la ponencia de Miquel de Moragas a este respecto y en relación con el movimiento olímpico: Televisión, deporte y movimiento olímpico: las próximas etapas de una sinergia (1994).

Al margen de la relación entre televisión y deporte, existe una ausencia total de trabajos que indaguen en el desarrollo histórico de la programación deportiva en España. Los principales estudios sobre la historia del medio no precisan ninguna información específica sobre estos contenidos y se centran fundamentalmente en el contexto político, los espacios informativos, los de entretenimiento y variedades así como los programas de fícción. Tan solo aparecen mínimas referencias a hechos muy concretos y generales que se repiten en la mayor parte de la bibliografía sobre el tema.

También es muy llamativa la carencia de bibliografía sobre la historia deportiva española que ayude a entender mejor esta relación. Al contrario que otros países, como en el caso de Estados Unidos o el Reino Unido, las obras históricas de las diferentes disciplinas deportivas son escasas, la mayor parte hacen referencia al fútbol y a los Juegos Olímpicos, y el resto están promovidos por pequeñas iniciativas personales o por las propias federaciones deportivas.

Por otro lado, es muy interesante contraponer el caso español con el de países anteriormente citados. En el extranjero existe una amplia gama de estudios encuadrados en lo que se conoce como "Mediasport" (relación entre los medios audiovisuales, fundamentalmente la televisión, y el deporte) que han analizado con mucho detalle todos las características de esta estrecha vinculación. Algunos buenos ejemplos los encontramos en los trabajos realizados por Johnson para la revista Sports Illustrated bajo el título "Television and Sport" (1970), la obra de Barnett sobre la transformación del deporte en televisión (1990), las compilaciones de Wenner en relación al "Mediasport" (1989 y 1998), el artículo de 1977 de Parente en 
la revista Journal of Communication en relación a la interdependencia del deporte y la televisión, el libro de Rader sobre la transformación del deporte americano a través de la pequeña pantalla (1984), la obra de Whannel en este mismo sentido en el Reino Unido (1992), los certeros análisis de la relación entre la televisión estadounidense y el deporte profesional de Klatell y Marcus y de Fortunato (1996 y 2001), las estrategias televisivas del Comité Olímpico Internacional de la obra de Larson y Park (1993), y el manual de referencia de los estudios sobre el deporte de Coakley y Dunning (2002).

También es muy interesante el análisis histórico del deporte estadounidense y su relación con los medios de comunicación de Rader (1990), así como las páginas de Edgerton y Ostroff en la obra TV Genres. A handbook and reference guide (1985). La lectura de estas obras junto con otras españolas de carácter más sociológico como las de Cagigal, Deporte, pulso de nuestro tiempo (1972), y García, Deporte y sociedad: las bases sociales del deporte en España (1982), han dado una visión más amplia este artículo y han permitido un análisis más detallado y preciso de unos temas poco explorados en el ámbito académico español.

Al margen de la literatura sobre el tema existente consultada, para lograr los objetivos planteados, primero se ha seleccionado una muestra adecuada que pueda ofrecernos una visión concreta y acertada de la realidad de cada período. En este caso, la muestra coincide con todos los programas y retransmisiones deportivas emitidas desde 1956 hasta 1988: cerca de medio millón de minutos dedicados por la televisión pública ${ }^{1}$.

La elaboración de la muestra se ha logrado gracias a tres fuentes fundamentales:

- La información recogida a través de la prensa nacional diaria de los períodos estudiados (parrillas de programación) que ha permitido saber con exactitud las retransmisiones y programas emitidos por TVE y las cadenas comerciales (y de este modo determinar el número de minutos y presencia en pantalla). En esta línea se ha realizado algún estudio de análisis de la programación con este procedimiento como en el caso de la obra de Gloria Gómez-Escalonilla, Programar televisión: análisis de los primeros cuarenta años de programación televisiva en España (2003). Aunque en este caso, se analizaba un número aleatorio de parrillas televisivas cada año, no todas, $\mathrm{y}$ sobre todos los contenidos generales. Para lograr este objetivo ha sido fundamental la hemeroteca "on-line" del periódico La Vanguardia que posee todos sus números digitalizados (cada página en formato "pdf") y que han hecho posible la tarea de recopilación de unos datos que difícilmente se hubiera realizado con el formato físico de la publicación.

- La segunda fuente han sido las revistas especializadas. Han sido muy útiles las relacionadas con la radiodifusión (sobre todo en el estudio de los orígenes de la televisión en España) pero especialmente hay que destacar una publicación en el período franquista: la revista Teleradio. De carácter semanal, esta revista vinculada a TVE es probablemente la mejor fuente de 
información sobre la evolución de la historia del medio en nuestro país, y que la mejor explica la opinión de la audiencia a través de numerosas cartas y opiniones de los televidentes.

- La tercera fuente ha sido el archivo videográfico de la Corporación RTVE, que ha permitido el visionado y comprobación de muchos de los datos obtenidos para la elaboración de la muestra, especialmente a partir del año 1966.

Con esta ambiciosa muestra, todo el universo existente, este trabajo expone de forma cronológica los hitos más importantes de la relación, así como las principales dificultades y problemas repetidos a lo largo de los años. La descripción narrativa de los hechos, tomando como base la literatura comentada y los datos obtenidos a través de la muestra, hacen de esta exposición la más completa de los estudios realizados sobre el tema hasta el momento.

\section{Los orígenes televisivos del deporte en España: Las primeras apariciones del fútbol}

La televisión llegó en 1956 a nuestro país, mucho más tarde que otros países europeos: Alemania (1935), Reino Unido (1936) e incluso Italia (1954). Este retraso en las primera experiencias prácticas de la televisión en España sugiere que la importancia del deporte (y el fútbol en particular) en la etapa experimental del medio fuese escasa en comparación con otros países.

Sin embargo, la etapa experimental del medio en España fue un período apasionante en el que el deporte se presentó como un anhelo televisivo que tuvo su plasmación práctica en las primeras exhibiciones públicas de los años cuarenta y en la programación experimental de TVE a comienzos de los cincuenta. España no fue un caso especial en relación a otros países pero sí presentó un gran interés por el fútbol desde sus orígenes, hecho que ha marcado todo el desarrollo televisivo hasta nuestros días.

La televisión alemana y la británica BBC fueron los primeros referentes del medio en el período previo a la segunda guerra mundial con la puesta en marcha de sus emisiones regulares. También, fueron pioneras en la realización de las iniciales retransmisiones deportivas.

La BBC irrumpió en estos contenidos con su transmisión en directo de la clásica prueba hípica del Gran Derby el 3 de junio de 1931 para en 1933 repetir la experiencia sobre una pantalla de 5,5 metros cuadrados diseñada por Baird. Desde esa primera cita, la $\mathrm{BBC}$ ha programado ininterrumpidamente esta prueba a lo largo de toda su historia ${ }^{2}$.

La cadena británica acometió, posteriormente, su gran objetivo: la emisión del primer partido de fútbol del mundo. Para ello el director de la BBC, Gerald Cock, negoció con la Asociación Inglesa de Fútbol para retransmitir el encuentro que enfrentaba a la selección inglesa con Escocia y, sobre todo, la final de la Copa 
Inglesa. A pesar de las reticencias de la Asociación, ya que no conocían el verdadero efecto de la televisión sobre el fútbol (tenían miedo de perder espectadores en los estadios), la BBC pudo televisar los dos acontecimientos. El 9 de abril de 1938 se retransmitió el primer partido de fútbol de la historia, el citado encuentro entre Inglaterra y Escocia (en el estadio de Wembley) y el 30 de abril la final de la Copa Inglesa entre el Preston North End y al Huddersfield Town con la presencia de la familia real británica ${ }^{3}$.

Por su parte, la televisión alemana fue la pionera en las emisiones regulares que se iniciaron el 29 de mayo de 1935. No existe constancia de importantes transmisiones deportivas previas a esta fecha, sin embargo, la televisión germana pasó a la historia del medio (en relación al deporte) al transmitir el primer gran acontecimiento deportivo de relevancia internacional: los Juegos Olímpicos de Berlín en 1936.

Estas Olimpiadas fueron las últimas antes de la segunda guerra mundial y unas de las más polémicas por el ascenso al poder de Hitler en Alemania. La tensa situación que vivía Europa y el discurso racista del régimen nazi provocaron las quejas de numerosos países ante el Comité Olímpico ${ }^{4}$.

El régimen de Hitler usó los Juegos Olímpicos como el escaparate perfecto para desarrollar la maquinaria propagandística y extender su idea de la "nueva Alemania" a todo el mundo. Se gastaron más de 30 millones de dólares en la organización que tuvo en el Estadio Olímpico (con capacidad para más de 110.000 espectadores) y en la lujosa villa para los atletas (a diez kilómetros de Berlín y rodeada de lagos y bosques) sus principales referentes. Por primera vez, la llama olímpica se trasladó desde Olimpia hasta el pebetero del estadio de la capital alemana y se consideraron a estos Juegos como los mejores de la historia en ese momento ${ }^{5}$.

Goebbels, que conocía el valor propagandístico del evento, preparó la mayor transmisión televisiva de la historia. Utilizó de forma oficial equipos electrónicos (hasta ese momento Alemania usaba el sistema mecánico) y desplegó más de 27 cámaras para registrar todas las competiciones deportivas. Se usó por primera vez la unidad móvil que rompía con la esclavitud del estudio central (donde se realizaban hasta entonces todos los programas). Además, fue la televisión pionera en el uso de las nuevas cámaras electrónicas con teleobjetivos: lentes que duplicaban la capacidad de captación, ofrecían imágenes más próximas y definidas y, como consecuencia de lo anterior, una dimensión expresiva similar a la del cine 6 .

La retransmisión de los Juegos Olímpicos, desde el 1 hasta el 15 de agosto de 1936, se realizó en circuito cerrado para una audiencia potencial de 150.000 espectadores (se contaban aquí los asistentes a locales públicos de recepción colectiva) y fue la primera demostración del poder de convocatoria de una retransmisión deportiva así como el bautismo de los Juegos Olímpicos en la pequeña pantalla (su presencia ha sido habitual hasta nuestros días).

El ejemplo británico y alemán tuvo su réplica en nuestro país, aunque de forma más lenta y progresiva. No es extraño, por lo tanto, que en las primeras retransmisiones radiofónicas en cadena de nuestro país, aquellas que inició Unión Radio en 1926, tuviesen prioridad en la programación los contenidos deportivos y los toros (que estuvieron muy unidos en toda la etapa franquista). En mayo de 1926 se emitió 
el primer combate de boxeo y justo un año más tarde el primer partido de fútbol retransmitido íntegramente por radio, un encuentro que enfrentó al Real Madrid y al Real Zaragoza ${ }^{7}$.

La experiencia radiofónica fue muy interesante porque marcó el tipo de programación y contenidos que años más tarde tomó la televisión española. En el fondo, la aparición de estos contenidos deportivos respondía a un interés generalizado por parte de la sociedad española. Algunos buenos ejemplos los encontramos en las reflexiones televisivas de las publicaciones radiofónicas de los años veinte y treinta. La revista Electrón escribía lo siguiente en diciembre de 1934:

¿Qué cabe exigir a la televisión? Examinemos, en primer término, la naturaleza de las satisfacciones visuales que el público puede esperar le ofrezca la televisión. Hagamos notar que todas las manifestaciones de la vida corriente han habituado el espíritu humano a la alianza continua y simultánea de dos percepciones: visual y auditiva [...]. Como ya hemos señalado, el público reclama en la actualidad que la audición radiofónica sea completada por la visión de los artistas. Ese mismo público reclamará rápidamente la difusión de manifestaciones especialmente visuales, como las que constituyen los reportajes radiofónicos (revistas, demostraciones deportivas, etc.) o las corresponden a la fórmula ya en vigor en Gran Bretaña.

Se hablaba de visualización radiofónica y se introducía otro elemento importante de la futura programación deportiva: la unión del deporte televisado y la retransmisión en directo (fundamentalmente en exteriores), su principal y más espectacular forma de representación.

Otros comentarios de esta época reafirmaban la idea de la visualización de las manifestaciones radiofónicas, entre ellas el deporte. Así lo comenta Francisco Javier Ruiz del Olmo en su obra, Los orígenes de la televisión (1997: 118):

A estas emisiones se unirán otras donde el elemento de contenido predominante será la transmisión a domicilio de cine. Asimismo, se predice que el público pediría con más rapidez manifestaciones visuales que se correspondieran en imagen con los reportajes radiofónicos de diversa índole como entrevistas, noticias de actualidad o retransmisiones deportivas.

También en este período, la revista especializada Radio y Televisión, dentro del famoso artículo "La televisión que viene" (1933), precisaba los contenidos más importantes del futuro televisivo, entre los que destacaban las manifestaciones deportivas:

Dentro de pocos años casi todas las emisoras del mundo transmitirán televisión, y acaso sonido en la misma onda, las imágenes se verán en una pantalla, detrás de la cual colocaremos uno o dos altavoces y tendremos en casa algo así como un cine sonoro en miniatura, pero con la inmensa ventaja de reflejar la pantalla lo que está sucediendo y no lo que ha pasado ya. Carreras de caballos, fútbol, toros, teatro, paisajes, calles con sus movimientos, en fin algo que hoy casi nos parece un sueño. 
Entre los deseos sobre los futuros contenidos de la televisión aparecía una nueva referencia a las retransmisiones deportivas pero, en este caso, se concretaban en las carreras de caballos y, lo más importante, en el fútbol que ha sido el principal referente de la programación deportiva de nuestra televisión a lo largo de la historia.

Las esperanzas de los años veinte y treinta se concretaron en las exhibiciones públicas de 1948. En especial, en las demostraciones de la RCA en Madrid donde apareció por primera vez el deporte televisado .

Los técnicos americanos realizaron en vivo y al aire libre sus pruebas gracias a las nuevas cámaras de tubo "orticón" con mayor sensibilidad a la luz. Eligieron, en primer lugar, la fallida corrida de toros de Vistalegre y, posteriormente, escogieron una retransmisión deportiva: un partido de baloncesto disputado el 19 de agosto de 1948. La presentación y comentarios recayeron en el profesional de Radio Nacional David Cubedo que explicaba así esta experiencia (Rodríguez y Martínez, 1992: 57):

Se trataba de transmitir un encuentro de baloncesto y yo apenas sabía de deportes, así que improvisé como pude. Cantaba a los jugadores por el número de sus camisetas y decía, por ejemplo: "el siete le pasa la pelota al cinco, etc.". Después de aquella retransmisión hicimos otras cosas distintas, como boxeo, bailes andaluces, lucha libre, etc.

Como bien comentaba Cubedo (posteriormente una de la caras más conocidas de la televisión española), tras el partido de baloncesto se transmitieron otros eventos deportivos como el boxeo o la lucha libre.

Es interesante resaltar la importancia del deporte en las primeras retransmisiones en exteriores y añadir una explicación a la presencia de deportes minoritarios (como el baloncesto, lucha libre o boxeo) en estas exhibiciones de la RCA. En este período, la tecnología de la televisión estadounidense no estaba suficientemente desarrollada para eventos deportivos que exigían un exigente despliegue de medios, como por ejemplo el fútbol. Por ello, se justificaba la presencia de deportes disputados en espacios más reducidos y fácilmente controlables por las cámaras de televisión así como la ausencia en estas exhibiciones de un deporte tan arraigado en España como el fútbol.

A pesar su escaso desarrollo televisivo (en comparación con otros muchos países), estos primeros eventos deportivos televisados en España nos dieron valiosas pistas sobre la futura importancia de la programación deportiva en la televisión española.

Especialmente interesantes fueron las primeras pruebas de TVE con el fútbol. En este caso, el primer partido de fútbol retransmitido por nuestra televisión que era, a la vez, la primera retransmisión realizada por la televisión española ${ }^{8}$.

TVE acometió esta primera retransmisión gracias a que la empresa Marconi cedió una de sus unidades móviles. El partido se celebró el 24 de octubre de 1954 y enfrentó al Real Madrid y al Racing de Santander.

La unidad llegó el mismo día del encuentro y se utilizó inmediatamente. Se eligió como comentarista del partido al afamado locutor de Radio Nacional Martín Navas. El locutor comentaba su experiencia (Rodríguez y Martínez, 1992: 219): 
De entrada me dijeron que me olvidara de la radio, que mi voz sería un mero apoyo para la imagen, que basase mi intervención en la narración de las tácticas de los equipos y que, sobre todo, estuviera cerca del monitor para comentar las imágenes. Me pusieron la cabeza llena de ideas nuevas. Pero me hacía ilusión aquella cosa que, entonces, no eran más que experiencias, pero todos estábamos convencidos de que iba a ser un medio absorbente, como luego se ha comprobado.

El técnico Manuel de las Doblas continuaba con su relato sobre las incidencias con la unidad móvil:

La unidad móvil Marconi era inglesa y estaba a cargo de un técnico inglés que no hablaba castellano. Yo chapurreaba algo de inglés, así que me destinaron al camión para hacer de intérprete y controlar un difícil asunto. El partido lo realizó Colina y fue un éxito.

Fue la primera de las muchas retransmisiones futbolísticas (y del Real Madrid en particular) que emitió TVE en sus primeros años de vida. De nuevo, el concepto de retransmisión en exteriores se unía ineludiblemente con un evento deportivo $\mathrm{y}$, además, se abría un período en el que el fútbol monopolizó buena parte de la atención de los espectadores de TVE. Los autores Rodríguez y Martínez lo expresan así en su obra Pioneros de la Televisión Española (1997: 219):

El deporte (y el fútbol en concreto) abrían significativamente el periodo de las retransmisiones deportivas, y no por casualidad. España entera vibraba de pasión por el deporte rey. Alfredo Di Stefano había llegado a las filas del Real Madrid en 1953. Ese mismo año consigue para su club el título de Liga que el equipo blanco buscaba desde hacía veintiuna temporadas. Con él se abre una época de esplendor para el fútbol español como no ha vuelto a conocer, una época que corona la consecución sucesiva, desde 1956, de las cinco primeras Copas de Europa. Para entonces el fútbol es ya una de las indiscutibles estrellas de la programación de TVE.

El anhelo de fútbol se hacía realidad pero sólo eran los primeros y balbuceantes pasos de la programación deportiva. A pesar del retraso con otros países, TVE había marcado las principales líneas de acción para sus primeros años y, de paso, el deporte había demostrado su importancia en estas emisiones iniciales.

\section{Fútbol y Televisión durante el monopolio de la Televisión pública (1956-1988)}

El 28 de octubre de 1956 se iniciaron en España las emisiones regulares de televisión. En ese momento, sólo existían 600 receptores en funcionamiento y la cobertura de la televisión pública, Televisión Española (TVE), apenas llegaba a los 70 kilómetros de los alrededores de Madrid. Como toda televisión en sus inicios, TVE desarrolló una programación muy experimental e improvisada en cuanto a los formatos y géneros de los espacios. 
Con esos humildes comienzos se iniciaba una etapa en la que la televisión pública tuvo el domino absoluto del mercado español (primero con TVE y luego con las televisiones autonómicas), impidiendo cualquier otro tipo de oferta televisiva de corte comercial. A este período se lo conoce como la etapa de monopolio de la televisión pública y se extenderá hasta el año 1988.

El modelo de televisión pública español, excepcional al contar con la presencia de la publicidad, impulsó el desarrollo de la programación deportiva y, especialmente, futbolística. En este período se pudieron definir claramente los rasgos de la relación. Por un lado, la televisión permitió dar visibilidad a las competiciones, especialidades deportivas y, especialmente, a la imagen de triunfo que se quería difundir en la sociedad (muy especialmente en el período franquista). Por otro, creaba problemas de compatibilidad con las propias instituciones deportivas, al provocar descensos en la asistencia a campos o modificación de horarios e incluso reglas del juego.

Desde la perspectiva televisiva, el futbol fue esencial para lograr el desarrollo de la televisión por toda España y la conexión con Europa, así como el desarrollo tecnológico del medio (color, transmisión por satélite, etc.). Los grandes problemas llegaron cuando los conflictos de intereses entre entidades deportivas (clubes) y televisiones (TVE y Televisiones Autonómicas, a partir de los años ochenta) afectaron a los presupuestos de las cadenas y posteriormente al de los clubes.

En las siguientes líneas se van a describir los rasgos citados anteriormente. En primer lugar se repasarán los principales hitos que permitieron la extensión televisiva por todo el país, su conexión con Europa y un importante desarrollo tecnológico. En segundo lugar se pondrá algún ejemplo de las inquietudes y problemas que provocó la relación entre televisión y fútbol.

\subsection{El fútbol como motor de desarrollo de la televisión}

Las experiencias previas, comentadas en el epígrafe anterior, hicieron posible la presencia del deporte en los primeros años de TVE. Durante estos años, el fútbol fue clave en la consolidación de la televisión en España ya que ayudó de forma definitiva al establecimiento de las primeras transmisiones en exteriores y a las primeras conexiones con otras televisiones europeas.

En 1957, las limitaciones de los estudios de producción de TVE impulsaron el interés por las retransmisiones en exteriores. Para potenciar estos programas, TVE adquirió en Inglaterra una unidad móvil PYE con 3 cámaras orticón y una mesa de sonido. Esta maquinaria permitió la transmisión de los primeros partidos de fútbol en las pantallas de TVE (todavía eran programas grabados), destacando entre ellos la final de la Copa de Europa que enfrentó al Real Madrid y al Fiorentina el 30 de mayo de 19579 .

El éxito de esta retransmisión y la consolidación de la nueva técnica permitió la emisión del primer encuentro de fútbol en directo el 27 de abril de 1958 . En un partido decisivo de Liga, el Atlético de Madrid y el Real Madrid se enfrentaron en el estadio Metropolitano por la consecución del título liguero. TVE utilizó un unidad 
móvil PYE que conectaba con sus estudios del Paseo de la Habana por medio de una antena parabólica con enlace microondas, situada en la terraza de un edificio cercano al estadio. El partido terminó con empate a uno en el marcador que otorgó al Real Madrid el título de liga y la retransmisión fue todo un éxito, circunstancia que permitió la regularización de las emisiones deportivas en televisión, entre otras, la aparición de forma regular de la final de la Copa de España de fútbol, la competición más antigua y con la presencia más regular de la programación deportiva española.

La segunda aportación del deporte a la televisión en este periodo fue el permitir el primer contacto otras televisiones europeas. El 13 de marzo de 1958, España jugó un partido de fútbol frente a la selección francesa en el campo del Parque de los Príncipes de París. El encuentro fue televisado para toda Francia por la televisión estatal RTF (Radio-Télevision Française). TVE ante la imposibilidad de poder contactar en directo con el país vecino, decidió filmar en 16 milímetros las imágenes televisadas a través de un aparato conectado a un monitor de salida justamente sincronizado con la frecuencia de la imagen televisiva. El artilugio se denominaba kinescopio, y sirvió en esos años para la grabación y posterior emisión de numerosos programas, entre ellos muchos deportivos. El partido fue revelado en París y traído a España en avión por la persona que comentaría posteriormente el encuentro grabado, Matías Prats. Además, este enfrentamiento entre Francia y España será recordado por ser uno de los primeros partidos de fútbol completamente patrocinados. TVE volvió a utilizar el sistema de partidos "kinescopados" con muchos de los partidos europeos que el Real Madrid jugó ese año, como por ejemplo el Vasas Real Madrid jugado en Budapest ${ }^{10}$.

Tras la consolidación de los primeros programas, TVE tenía como principal objetivo el extender la red de televisión a todo el país. Ya en 1955, se había creado el Plan Nacional de Televisión que establecía la creación, en primer lugar, de emisoras en Madrid y Barcelona, en segundo lugar, el enlace Madrid - Barcelona y la conexión con la red de Eurovisión y por último la extensión progresiva al resto de las ciudades españolas. En la extensión de esta red, el deporte tuvo de nuevo un papel decisivo.

Para celebrar la inauguración del centro emisor de Zaragoza (clave para la conexión con Barcelona) el 12 de octubre de 1958, TVE emitió una corrida de toros y, de nuevo, un partido de fútbol. Sin embargo, el deporte jugaría un papel aún más importante en la llegada de la televisión a Barcelona.

En la primera semana de febrero de 1959, comenzaron las emisiones experimentales de TVE en la Ciudad Condal. Los ensayos tuvieron un gran éxito y se decidió afrontar la prueba de fuego de la emisora de Barcelona con la retransmisión del partido de Liga de Fútbol que enfrentaba al Real Madrid y el Barcelona.

El encuentro se disputaba el domingo 15 de febrero de 1959 en el estadio de Chamartín de Madrid. En la semana previa, se extendió el rumor de que el partido se iba a retransmitir a toda Barcelona por televisión. Ante la posibilidad de poder presenciar un partido de tanta rivalidad y ante un hecho histórico de tal calibre (inauguración de la emisiones en Barcelona), los barceloneses compraron prácticamente todos los televisores de las tiendas de la ciudad. Tal fue la avalancha de ventas de televisores, que hasta los aparatos de los escaparates fueron vendidos a precio de 
mercado negro. Se cree que desde el jueves 12 de febrero hasta el sábado 14 se compraron casi seis mil televisores ${ }^{11}$.

TVE realizó un gran despliegue en el campo con la utilización de cuatro cámaras, algo nada habitual en la época. Era un partido histórico ya que era el primer Real Madrid - Barcelona que se televisaba. Con la retransmisión del partido se mostraron algunas de las posibilidades del fútbol como programa televisivo. La cualidad más clara, el gran potencial publicitario de este tipo de eventos. Los días previos al encuentro, una compañía cervecera catalana ofreció al Real Madrid medio millón de pesetas por los derechos de transmisión. El gobierno franquista lo impidió al considerar que el partido era de interés general y no podía estar supeditado a los intereses particulares de los clubes. La Dirección General de Radiodifusión solucionó el problema pagando 150.000 pesetas al Real Madrid y otra cantidad menor al Español que jugaba en Barcelona esa tarde y podía salir perjudicado en la asistencia al campo. Además, para que no se volviese a dar de nuevo esa situación, el régimen aprobó un Decreto del Ministerio de Información y Turismo por el que se permitía la adquisición de los derechos de transmisión por parte de TVE en caso de existir un evento deportivo de interés público. Es un precedente histórico claro de las posteriores medidas legales tomadas con respecto al fútbol en los años 90 con la Ley de Interés General y una constatación clara del importante papel del deporte y en especial del fútbol como medio de expansión de la televisión y las ideas del régimen ${ }^{12}$.

A finales del año 1959, la emisora de Barcelona se había consolidado y tenía la experiencia suficiente para afrontar el reto de la conexión con Eurovisión. El 21 de diciembre de 1959, TVE realizó el primer contacto serio con la Red Europea de Televisión al televisar la llegada a Madrid del presidente estadounidense Eisenhower. Fue el primer producto realizado íntegramente para la difusión en la red de Eurovisión. Sin embargo, el método utilizado fue el kinescopado al no contar TVE con los medios para poder realizar una conexión en directo con el exterior.

El paso decisivo se dio en marzo de 1960. De nuevo el fútbol fue protagonista absoluto con la transmisión en directo de un partido de Copa de Europa entre el Real Madrid y el OGC Niza. Fue la primera transmisión en directo de TVE para Eurovisión. En concreto, el partido fue presenciado por 50 millones de espectadores en países como Francia, Luxemburgo, Alemania, Bélgica, Italia etc. ${ }^{13}$

Es interesante reseñar cómo la pieza clave de la colaboración entre TVE y Eurovisión fue el fútbol. La razón es muy sencilla. España, aislada políticamente, podía integrarse, en cierta medida, a Europa gracias al fútbol y en concreto al Real Madrid, su principal representante.

La creación en 1955 de la Copa de Europa de fútbol y en 1957 de la Eurocopa de Naciones fue una pieza clave en la integración europea no sólo de España sino del resto de países europeos. El fútbol era uno de los principales elementos culturales de todos estos países y servía a la perfección al objetivo de la Red de Eurovisión que era el intercambio cultural de programas. No podemos obviar, tampoco, que las competiciones surgieron con unos intereses económicos concretos que encontraban en la televisión su principal aliado. Era un anticipo de lo que ocurriría posteriormente en los años ochenta y noventa. 
Con este argumento, TVE volvió a transmitir el 18 de mayo de 1960 la final de la Copa de Europa que enfrentó al Real Madrid y al Einstrancht de Frankfurt. Este partido fue histórico por tratarse de las primeras imágenes de Eurovisión recibidas desde el exterior y en directo, además, supuso el quinto triunfo consecutivo del Real Madrid en la Copa de Europa, un record histórico. La conexión definitiva con Eurovisión se realizaría el 15 de diciembre de 1960 con la retransmisión de la boda entre los monarcas Balduino y Fabiola de Bélgica.

Una vez terminada la expansión de TVE a prácticamente todo el territorio nacional, durante los años sesenta y setenta van a establecerse dos nuevos objetivos: el nacimiento de un segundo canal de televisión y la aparición del color en las retransmisiones. Al igual que en los casos anteriores, el fútbol jugará un papel muy importante.

El 1 de enero de 1965 comenzaron las emisiones en pruebas de la segunda cadena de Televisión Española, también conocida como la "UHF" ya que es en esa frecuencia por la que emitirá habitualmente. El 15 de noviembre de 1966 se inauguraron las emisiones regulares de la segunda cadena. La expansión y creación del nuevo canal fue muy rápida, sin embargo, sólo las grandes ciudades pudieron disfrutar en los primeros años de esta nueva oferta televisiva, ya que la expansión de la señal se frenó a finales de los años sesenta. No será hasta finales de los setenta y, en especial, a partir de 1982 cuando con la celebración del Mundial de Fútbol de nuestro país el segundo canal se extienda a todo el territorio. La transmisión de este evento para todo el mundo permitió la modernización de Televisión Española con la creación de los estudios de producción de Sant Cugat en Barcelona y de emisión de Torrespaña (Madrid) en una nueva muestra del papel decisivo del deporte en el avance de la televisión de nuestro país ${ }^{14}$.

El segundo canal, que nació para resolver los problemas de saturación de programas de la primera cadena, se especializó en contenidos culturales y de carácter minoritario. Tras el Mundial de Fútbol de España en 1982 se fue transformando en un canal donde el deporte era el principal argumento de programación. En 1988, la segunda cadena de TVE fue la televisión que más horas dedicó a la programación olímpica de toda Europa ${ }^{15}$.

Otro de los objetivos de TVE fue la progresiva implantación del color en las transmisiones. En diciembre de 1965, las emisoras de TVE en Madrid y Barcelona comenzaron a emitir en color de forma experimental a través de circuito cerrado. Estas primeras emisiones se realizaron a través de los laboratorios de la ORTF francesa en el sistema SECAM ${ }^{16}$.

Durante el primer año de experimentación, la emisora de Madrid utilizó los tres sistemas de color existentes en una programación de pruebas que duraba desde las nueve de la noche hasta las doce de la madrugada.

El primer programa emitido en color, en pruebas, fue un combate de boxeo. El 8 de marzo de 1971, Mohamed Ali y Joe Frazier se enfrentaron por el título de los pesos pesados, en un combate transmitido a las cuatro de la madrugada.

En el resto de Europa, el deporte también es uno de los principales medios para estrenar las nuevas tecnologías, en este caso el color. En Francia, por ejemplo, los 
Juegos Olímpicos de Grenoble de 1968 fueron el reclamo utilizado por la televisión francesa para promocionar las nuevas emisiones en color ${ }^{17}$.

En España, con motivo de las olimpiadas de Munich de 1972, TVE comienza las emisiones regulares en color. En 1973, se adquieren las primeras cámaras y equipos de producción en color, mientras que las emisiones en este sistema llegan a las diez horas. La continuidad de las emisiones tiene lugar con la transmisión del Mundial de Fútbol de Alemania de 1974 y un año después casi un tercio de la programación se emite en color a pesar de que todavía no se había decidido el sistema oficial de transmisión en color. A partir de ese momento, los programas deportivos, dramáticos, informativos, telefilmes se emiten en color aunque el desarrollo es lento.

No podemos olvidarnos de la introducción del satélite como elemento clave de la emisión de grandes eventos internacionales en los que el deporte tuvo un lugar privilegiado. Gracias a la introducción de la tecnología por satélite, los grandes eventos deportivos como los Juegos Olímpicos (a partir de Tokyo en 1964), la Copa Davis en 1967 (con la primera retransmisión en horario de madrugrada de la historia de la televisión española) o Campeonatos Mundiales de fútbol disputados en otros continentes (México en 1970) pudieron tener cabida en la programación de Televisión Española y pronto se convirtieron en programas estrellas de la cadena.

\subsection{Relación de necesidad, relación problemática}

Tras muy pocos años de relación entre el fútbol, rápidamente surgieron los primeros problemas y dudas sobre la conveniencia de las retransmisiones futbolísticas. La mayor parte de las discusiones se centraron en los beneficios o perjuicios de la televisión para las organizaciones deportivas.

El debate sobre los efectos negativos del medio televisivo ha sido frecuente en todo el mundo y muy estudiado en el extranjero. Existen numerosos estudios teóricos sobre el tema, aunque, entre ellos, destacan los artículos de Glasser y McIntosh ${ }^{18}$.

Estos autores describen los más importantes efectos negativos de la influencia televisiva: el descenso de la asistencia a los campos, la comercialización del juego y pérdida del espíritu deportivo, la transformación del reglamento y de la naturaleza del deporte así como la excesiva dependencia económica de la televisión.

Sin embargo, otros trabajos han profundizado en los beneficios de la relación entre televisión y deporte. Aquí el más destacado es el ya citado texto de Donald Parente, que señala las principales ventajas: la consolidación del profesionalismo, el reforzamiento de las estructuras deportivas a nivel nacional e internacional, el descubrimiento de nuevas disciplinas deportivas y el reconocimiento de los deportistas como verdaderas estrellas del juego.

Los primeros pasos de la televisión deportiva en Francia o el Reino Unido estuvieron marcados por las dudas sobre la conveniencia del nuevo medio para el deporte, en especial sobre su influencia en la asistencia a los terrenos de juego.

En España, a partir de 1961 surgieron voces críticas que culparon a la televisión de la bajada de asistencia a los campos de fútbol. Este debate se plasmó en las páginas de la revista Teleradio a través de su colaborador Manuel Rosa, que defendía 
el papel de la televisión como impulsor del deporte. Además, profundizaba en las posibles causas del descenso de espectadores ${ }^{19}$ :

Negar el efecto publicitario de la televisión es negar la luz del día. Conocemos a muchos aficionados al fútbol que han sido ganados por las retransmisiones de televisión. Estas retransmisiones despiertan el interés de muchos que jamás sintieron curiosidad por un estadio; el virus de la afición llegó hasta ellos, los busca en su propio cuarto de estar y acaba captándolos. Tal espectador de televisión, una vez convertido en "hincha" no se conformará ya con ver los partidos en el pequeño rectángulo de su televisor y buscará el clima apasionado de los estadios, la sal y la pimienta de "estar allí". Claro es que si hace mal tiempo, muchos aficionados tibios o de economía débil elegirán, a veces, el televisor de un bar, donde por el precio del café verán el partido. En cuanto al aficionado dudoso, váyase en buena hora, que bien puede cambiarse por el dilatado número de nuevos aficionados entusiastas que la televisión, indudablemente, capta. Y en cuanto a los de economía precaria, tengamos para ellos una mínima dosis de consideración, que roza la justicia social, y no queramos tampoco violentarles su presupuesto, porque sería poco decorosa la pretensión de basar todo este aparato millonario sobre las espaldas de los que menos tienen, de los que, con unas ganas locas de ir al campo de fútbol, se tienen que conformar con verlo en el televisor de un bar o de un amigo.

A pesar de la ferviente defensa de la televisión (hay que recordar que Teleradio era una revista muy cercana a TVE), el artículo de Manuel Rosa era muy interesante ya que planteaba problemas comunes en todos los países europeos. No menos importante era la defensa a ultranza de las retransmisiones futbolísticas con argumentos como la "justicia social" o el "bien común". Muchas de estas razones se utilizaron años más tarde como justificación del interés general de ciertas retransmisiones deportivas.

El debate sobre los efectos de la televisión (especialmente en la asistencia a los campos) no llegó y todavía hoy no ha llegado a una solución en firme. En ciertas circunstancias, el fútbol televisado reduce el aforo de los campos, mientras que en otras parece tener poco o ningún efecto. Por ejemplo, el aumento de las transmisiones futbolísticas en directo de la televisión británica en los últimos años ha llegado de forma paralela al constante crecimiento de la asistencia a los terrenos de juego. Es un área de estudio compleja y un problema con muchas variables: puede influir la historia y la tradición del club, su actual posición en la Liga, su estilo de juego, el contrario, el tiempo, la presencia o ausencia de jugadores estrella, el nivel del paro en una zona, el período del año (verano, primavera, etc.) o la existencia de formas alternativas de ocio (donde la televisión es otra más) ${ }^{20}$.

Los problemas en la relación tuvieron una extensión clara en la lucha por los derechos de retransmisión A comienzos de los ochenta aparecen las primeras cadenas regionales públicas (televisiones autonómicas) que rompen con el monopolio televisivo de 26 años de TVE21.

Estas nuevas televisiones autonómicas utilizaron el deporte, de la misma manera que lo había hecho anteriormente TVE, para darse a conocer y potenciar su programación. Especialmente significativos fueron los intentos por retransmitir los partidos 
de fútbol del Campeonato Nacional de Liga que implicaban a equipos de su región como la Real Sociedad y el Athlétic de Bilbao (en el caso de la ETB) o Barcelona y Espanyol (en la TV3). La presión de estas nuevas televisiones y la necesidad de la Liga de Fútbol Profesional (el estamento encargado de organizar el Campeonato) por obtener más beneficios posibilitaron la retransmisión de partidos por las cadenas autonómicas ampliando una oferta que hasta esos momentos había quedado reducida a la programación de TVE. La fuerte apuesta de las televisiones autonómicas se confirmó en 1989 con la firma de un contrato exclusivo para la retransmisión en abierto de los partidos del Campeonato Nacional de Liga, quedándose TVE fuera del contrato por primera vez en la historia.

El interés de las televisiones autonómicas no se redujo al fútbol nacional ya que durante los años ochenta retransmitieron numerosos partidos de las competiciones internacionales de fútbol, así como otras disciplinas deportiva como baloncesto, balonmano, fútbol americano, Fórmula 1, etc. La competencia provocó un importante problema de sobredimensión del producto futbolístico y una excesiva dependencia de las instituciones deportivas del dinero de las televisiones ${ }^{22}$. Todos los problemas y beneficios de la relación se habían planteado durante un período decisivo para la relación entre fútbol y televisión en España.

\section{Conclusiones.}

Tras la exposición de estos casos se pueden extraer las siguientes conclusiones:

- La relación de necesidad entre fútbol y televisión no es un fenómeno nuevo. De hecho, el origen de la unión la encontramos con la aparición de las primeras retransmisiones futbolísticas y desde ese primer momento ya se establecen las bases de una relación de dependencia.

- La televisión se desarrolla y expande gracias a la dimensión social del fútbol y su tirón popular (el ejemplo de Barcelona es el más claro). Además el fútbol es protagonista de la mayoría de los hitos de modernización y mejora tecnológica del medio (color, satélite, etc.). Por otro lado, el fútbol consigue la difusión necesaria para consolidar su posición de deporte "rey", al igual que sus protagonistas, los futbolistas. No podemos entender la aparición del deporte profesionalizado y la consolidación de clubes y torneos sin la presencia de la televisión (como el caso de la Copa de Europa).

- Esta relación ha provocado grandes beneficios pero también perjuicios muy serios. La modificación de reglas deportivas, la excesiva comercialización del deporte, la dependencia del dinero de la televisión, la reducción de la asistencia a los campos o los problemas de los derechos de retransmisión son solo unos pocos ejemplos de la complejidad de esta unión.

- Con la aparición de nuevas televisiones, el ejemplo de TVE se extiende. Las televisiones autonómicas y las nuevas televisiones comerciales aprovechan 
el arraigo y popularidad de las retransmisiones deportivas como un elemento esencial de sus estrategias de programación.

- La televisión española siguió el ejemplo de otras cadenas europeas en relación a la programación deportiva. Sin embargo, la dimensión social del fútbol en España y las propuestas pioneras de TVE (como la emisión regular de partidos de Liga de forma regular desde 1963) hacen del caso español una referencia en la historia televisiva.

\section{Bibliografía}

\section{Libros}

ALCOBA, A. (1997). Deporte y comunicación. Madrid: Dirección General de Deportes de la Comunidad Autónoma de Madrid.

ALONSO, F. (1999). Sogecable descodificado: cifras y claves empresariales de Canal + en España, Madrid: Fragua.

ANSÓN, R. (2004). El olimpismo. Madrid: Universidad Camilo José Cela.

ARIAS, A. (1970). La televisión española. Madrid: Publicaciones españolas.

BAGET, J. (1975). 18 años de TVE. Barcelona: Diáfora.

(1995). Historia de la televisión en España: 1956-1975. Barcelona: Feed-Back Ediciones.

BARNETT, S. (1990). Games and sets: the Changing Face of Sport on Television. Londres: British Film Institute.

BLANCO, J. (2000). Las retransmisiones deportivas televisadas como género periodístico, espectacular y dramático. Bellaterra: Universitat Autònoma de Barcelona.

BONAUT, J. (2009). Televisión y deporte. Origen y desarrollo histórico de la programación deportiva española (1956-1975). Buenos Aires: Librosenred.

BRIGGS, A. (1985). BBC: the first fifty years. Oxford: University Press.

CAGIGAL, J. (1972). Deporte, pulso de nuestro tiempo. Madrid: Editora Nacional.

COAKLEY, J. y DUNNING, E. (2002). Handbook of sports studies. Londres: Sage.

DEL OLMO, F. (1997). Orígenes de la televisión en España. Málaga: Universidad de Málaga.

EDGERTON, G. y OSTROFF, D. (1985). "Sports Telecasting”. En ROSE, B. (ed.), TV Genres. A handbook and reference guide. Westport: Greeenwood Press, pp. 257-286.

FAUS, A. (1995). La era audiovisual: historia de los primeros cien años de la radio y la televisión. Barcelona: Eiunsa.

FORTUNATO, J. (2002). The ultimate assist: the relationship and broadcast strategies of the NBA and TV Networks. Cresskill: Hampton Press.

GARCÍA, M. (1982). Deporte y sociedad: las bases sociales del deporte en España. Madrid: Dirección General de Juventud y Promoción Socio-Cultural.

GEOFFREY, G. (1949). The Official history of the F.A. Cup. Londres: Heinemann.

GÓMEZ-ESCALONILLA, G. (2003). Programar televisión: análisis de los primeros cuarenta años de programación televisiva en España. Madrid: Universidad Rey Juan Carlos I. 
JEANNENEY, J. (1999). L'écho du siècle: dictionnaire historique de la radio et de la télévision en France. París: Hachette.

KLATELL, D. y MARCUS, N. (1996). Inside big-time sports: television, money and the fans. Nueva York: MasterMedia.

LARSON, J. y PARK, H. (1993). Global television and the politics of the Seoul Olympics. Boulder (Colorado): Westview Press.

MANDELL, R. (1987). The nazi Olympics. Urbana: University of Illinois.

MORAGAS, M. (1994). Televisión, deporte y movimiento olímpico: las próximas etapas de una sinergia. Barcelona: Centre d'Estudis Olímpics UAB.

PALACIO, M. (2001). Historia de la televisión en España. Barcelona: Gedisa.

PÉREZ, J. (1989). "Peculiaridades de una televisión de estado". En TIMOTEO, J. (ed.) (1989). Historia de los medios de comunicación en España. Periodismo, imagen y publicidad (1900-1990). Barcelona: Ariel.

RADER, B. (1984). In it's own image: how television has transformed Sports. Nueva York: Free Press

(1990). American sports: from the age of folk games to the age of televised Sports. Englewood Cliffs: Prentice Hall.

RODRÍGUEZ, I. y MARTÍNEZ, J. Pioneros de la Televisión Española. Barcelona: Mitre.

VARELA, A. (1997). Las audiencias de las retransmisiones y programas de deportes de Televisión de Galicia desde 1990 hasta 1996 (Tesis doctoral). Santiago de Compostela: Ciencias da Comunicación

WENNER, L. (1989). Media, sports and society. Newbury Park: Sage. (1998). Mediasport. Londres: Routledge.

WHANNEL, G. (1992). Fields in vision: television sport and cultural transformation. Londres: Routledge.

\section{Revistas}

BONAUT, J. (2008). "La influencia de la programación deportiva en el desarrollo histórico de TVE durante el monopolio de la televisión pública (1956-1988)". En Comunicación y Sociedad, Vol. 21. Núm. 1., pp. 103-136.

Electrón (1934). “Actualidad y porvenir de la televisión”, n 18, I.XII.1934.

GLASSER, B. (1985). “Is TV good or bad for sports?”. En Sport and Leisure, mayojunio.

MCINTOSH, P. (1974). "Mass media: friends or foes in sport”. En Quest, junio.

PARENTE, D. (1977). "The interdependence of sport and television”. En Journal of Communication, 27 (3), pp.128-132.

Radio y Televisión (1933). "La televisión que viene", nº 1, marzo.

Sports Illustrated (1969). "Television and sport”, 22 dic. 1969 - 26 ene. 1970.

Teleradio, "En torno al fútbol y la televisión", no 208, 1961, p. 7.

Teleradio, "Exhibición de TV-Color", n 410, 1965, pp. 17.19.

\section{Periódicos}

El País, "Más de diez mil millones invertirá TVE en el Mundial-82”, 02-07-1980. 
El País, "TVE realizará el despliegue informativo europeo más importante con motivo de los JJ.OO. de Seúl”, 04-08-1988.

\section{Notas}

1 BONAUT, J. (2009). Televisión y deporte. Origen y desarrollo histórico de la programación deportiva española (1956-1975). Buenos Aires: Librosenred.

2 BRIGGS, A. (1985). BBC: the first fifty years. Oxford: University Press, p. 158.

3 GEOFFrEY, G. (1949). The Official history of the F.A. Cup. Londres: Heinemann.

4 ANSÓN, R. (2004). El olimpismo. Madrid: Universidad Camilo José Cela, pp. $315-$ 317.

5 Para más detalles sobre los Juegos Olímpicos de Berlín, vid. MANDELL, R. (1987). The nazi Olympics. Urbana: University of Illinois.

6 FAUS, A. (1995). La era audiovisual: historia de los primeros cien años de la radio y la televisión. Barcelona: Eiunsa, p. 188.

7 ARIAS, A. (1970). La televisión española. Madrid: Publicaciones españolas, p. 17.

8 BAGET, J. (1995). Historia de la televisión en España: 1956-1975. Barcelona: FeedBack Ediciones, p. 21.

9 BAGET, J. (1975). 18 años de TVE. Barcelona: Diáfora, p. 10.

10 PALACIO, M. (2001). Historia de la televisión en España. Barcelona: Gedisa, p. 41.

11 BAGET, J. (1993), op. cit., p. 54.

12 PALACIO, M. (2001), op. cit., p. 55.

13 PÉREZ, J. (1989). "Peculiaridades de una televisión de estado". En TIMOTEO, J. (ed.) (1989). Historia de los medios de comunicación en España. Periodismo, imagen y publicidad (1900-1990). Barcelona: Ariel, pp. 304-325.

14 El País, "Más de diez mil millones invertirá TVE en el Mundial-82”, 02-07-1980.

15 El País, "TVE realizará el despliegue informativo europeo más importante con motivo de los JJ.OO. de Seúl”, 04-08-1988.

16 Teleradio, "Exhibición de TV-Color", no 410, 1965, pp. 17.19.

17 JEANNENEY, J. (1999). L'écho du siècle: dictionnaire historique de la radio et de la télévision en France. París: Hachette, pp. 469-479.

18 Los dos artículos referidos son: GLASSER, B. (1985). "Is TV good or bad for sports?". En Sport and Leisure, mayo-junio, p. 24 y MCINTOSH, P. (1974). "Mass media: friends or foes in sport”. En Quest, junio, pp. 35-45.

19 Teleradio, "En torno al fútbol y la televisión”, n 208, 1961, p. 7. 
20 BARNETT, S. (2001). Games and sets: the changing face of sport in television. Londres: British Film Institute, pp. 13-14.

21 ALONSO, F. (1999). Sogecable descodificado: cifras y claves empresariales de Canal + en España, Madrid: Fragua, p. 171.

22 BONAUT, J. (2008). "La influencia de la programación deportiva en el desarrollo histórico de TVE durante el monopolio de la televisión pública (1956-1988)". En Comunicación y Sociedad, Vol. 21. Núm. 1., pp. 103-136.

\section{El autor}

Joseba Bonaut es doctor en Comunicación Audiovisual (2006) por la Universidad de Navarra, y en la actualidad profesor de Historia de los Medios Audiovisuales e Historia Estética del Cine en la Universidad San Jorge de Zaragoza, al tiempo de Decano de su Facultad de Comunicación. Parte de su tesis doctoral, Televisión y deporte: influencia de la programación deportiva en el desarrollo histórico de TVE durante el monopolio de la televisión pública (1956-1988), fue reconocida en el año 2008 con el Primer Premio de la Vigésima Edición de los Premios a la Investigación en Comunicación Audiovisual del Consejo Audiovisual de Cataluña (CAC). 